Currently work is being carried out to calibrate the reentrainment model against measurements taken on site at Lethabo Power Station.

\section{CONCLUSIONS}

- The skew gas flow technology has proven to be cost effective ESP enhancement technology.

- The technology is applicable to a wide variety of dusts and in conjunction with $\mathrm{SO} 3$ flue gas conditioning.

- To further improve the benefit of this technology continued research is being conducted with the emphasis on the manipulation of the dust particles before entry to the collection chamber

- The application of the skew gas flow technology has been greatly enhanced by the CFD simulations. The combination of the manipulation of both the flow and dust and the reduction of reentrainment will results in the full optimisation of the ESP collection efficiency.

- The application of CFD modelling has substantially reduced the outage time required to successfully implement the technology.

- The returns of investments are substantial in comparison to other available enhancement technologies.

\section{REFERENCES}

1. D. Gibson, Matimba Power Station ESP Flow Distribution, Evaluation and Correction Eskom internal report, TRR/P93/061.

2. D. Gibson, Precipitator skew gas flow technology, Eskom internal report. TRR/P93/061.

3. D. Gibson, W. Schmitz, A.G.Hein, Electrostatic Precipitator Skew Gas Flow Technology, Application and Quantification 7th ICESP, Kyongju, Korea Sept. 1998.

4. Schmitz, W., CFD modelling of a complete ESP: Progress report, Eskom internal report. TRR/P96/321

5. Schmitz, W., CFD modelling of a complete ESP: Progress report, Eskom internal report. TRR/P97/404

6. Schmitz, W., CFD modelling of a complete ESP: Progress report, Eskom internal report, TRR/P98/514

7. Schmitz, W., CFD modelling of a complete ESP: Progress report, Eskom internal report, RES/RE/00/10843.

8. White, H. J., Industrial electrostatic precipitation, International Society for Electrostatic Precipitation

\title{
BRAZIER DESIGN FOR MINIMUM SMOKE EMISSION
}

\author{
G P SLABBERT \\ GJMC, P O Box 32243, Braamfontein, 2017
}

\section{INTRODUCTION}

Smoke from braziers (imbawula's, paola's) has been a thorn in the flesh of officials doing air pollution control in urban areas for many years. Everybody has seen the bellowing smoke from these imbawula's during winter mornings in the CBD of Johannesburg. It sometimes even reduces the visibility so much that even the road cannot be seen which is a traffic hazard. This pollution is especially bad during during the mealie season when informal traders braai mealies to sell it to the passing trade. Informal traders cooking food in fact has become part of the everyday life in most urban areas in South Africa. Braziers are also used in former black townships and in informal settlements for domestic cooking.

\section{LAW ENFORCEMENT}

Law enforcement as far as braziers is concerned is and was always very difficult if not impossible. The Atmospheric Pollution Prevention Act prohibits smoke from fuel-burning appliances with a certain density depending on whether the appliance is in an industrial or a residential area. Normally the appliance is on a premises where an occupier or an owner can be prosecuted if necessary. Informal traders use a piece of the sidewalk in the $\mathrm{CBD}$ or a vacant piece of government or provincial land where nobody can be prosecuted. Some even sell hot embers to other informal traders. Confiscation of braziers may even lead to attacks on officials and is counterproductive as this is their livelihood. These arguments however do 
not solve the air pollution problem from these fuelburning appliances.

\section{EDUCATION}

Education of people using braziers remains the only lasting solution to this problem. Everybody realises that coal-fire smoke is unhealthy, that is why nobody stands next to such a fire, unless the smoke has disappeared and only the heat remains. Education of how to make a fire with very little smoke emission remains the ultimate goal for law enforcers at local authorities.

\section{OLD BRAZIER DESIGN}

Braziers used to be just an old tin with holes in it for draft to keep the fire going. Users of these appliances simply put paper and wood at the bottom, kindle the fire and add the coal on top. This leads to smoke emission for some time before only the hot embers remain. Every time coal is added in sufficient quantities to keep the fire going it smokes all over again.

\section{SCOTCH METHOD}

This method originated possibly in the 1960's to save on coal consumption with a concomitant reduction in smoke emission. The former Transvaal Coal Owner's Association (TCOA) presented a course on this method to officials doing air pollution control. This method is simply packing a coal fire in a hot water boiler upside down. With this fire the coal is put at the bottom with the paper and wood at the top. When the fire is kindled the burns from the top down, instead of from the bottom up. This method removes the "volatiles" from the air stream which mainly consist of $\mathrm{SO}_{2}$. particulate matter, hydrocarbons and smaller quantities of aromatics, etc. This method burns slowly, it is unacceptable to informal traders and works well in a hot water boiler and not really in a brazier.

\section{NEW BRAZIER DESIGN}

Round about three or four years ago a lot of complaints were received about smoke from braziers used by informal traders. We decided to look at this issue of imbawula smoke again. The environmental inspectors started experimenting with changing the traditional imbawula to one that does not smoke or that smoke very little. One of the inspectors visited Richlab (SGS in Midrand) and started experimenting with this new design. Eventually it was decided to try and copy the traditional hot water boiler with primary-, secondary air as well as a chimney. After a lot of effort and frustration the design was finalised. The following steps must be taken in setting up this fuel-burning appliance:
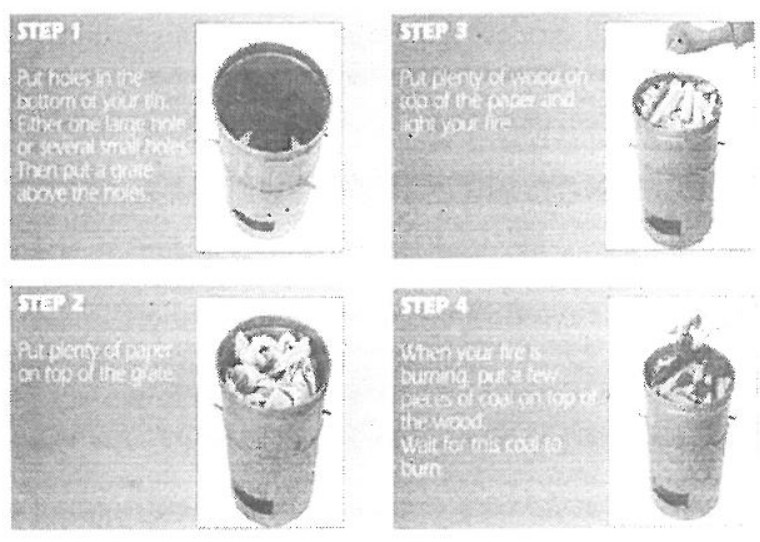

\section{PAMPHLET ON BRAZIER DESIGN}

A pamphlet on this design was developed by GJMC's Public Relations Office soon after the design was finalised. This pamphlet shows how to make this brazier.

\section{DEMONSTRATIONS TO INFORMAL TRADERS}

Demonstrations of this imbawula design to informal traders were immediately undertaken in the "old" Johannesburg area before the Greater Johannesburg Metropolitan Council was formed. Imbawula's were not distributed to informal traders, the design was just demonstrated to them. The result of this was that people stuck to the old design.

\section{MIDRAND METROPOLITAN LOCAL COUNCIL}

About six months ago one of G J M C 's pamphlets on this new imbawula design was given to Midrand Metropolitan Local Council (MMLC). A program was organized whereby entrepreneurs were trained, tins were bought and supplied to them and eventually have it tested by the CSIR or the SABS for smoke emission. Officials from MMLC will tell delegates at this conference all about this and demonstrate exactly how it actually works.

\section{CONCLUSION}

This new design can really make a difference to the contribution of ail pollution from imbawulas to the total amount of air pollution in our urban areas, especially on winter mornings with temperature inversions on the Highveld. Marketing and distribution of these imbawulas as it is undertaken by MMLC. seems to be the ultimate application of this design to make it acceptable to informal traders and make it's use as widespread as possible. 